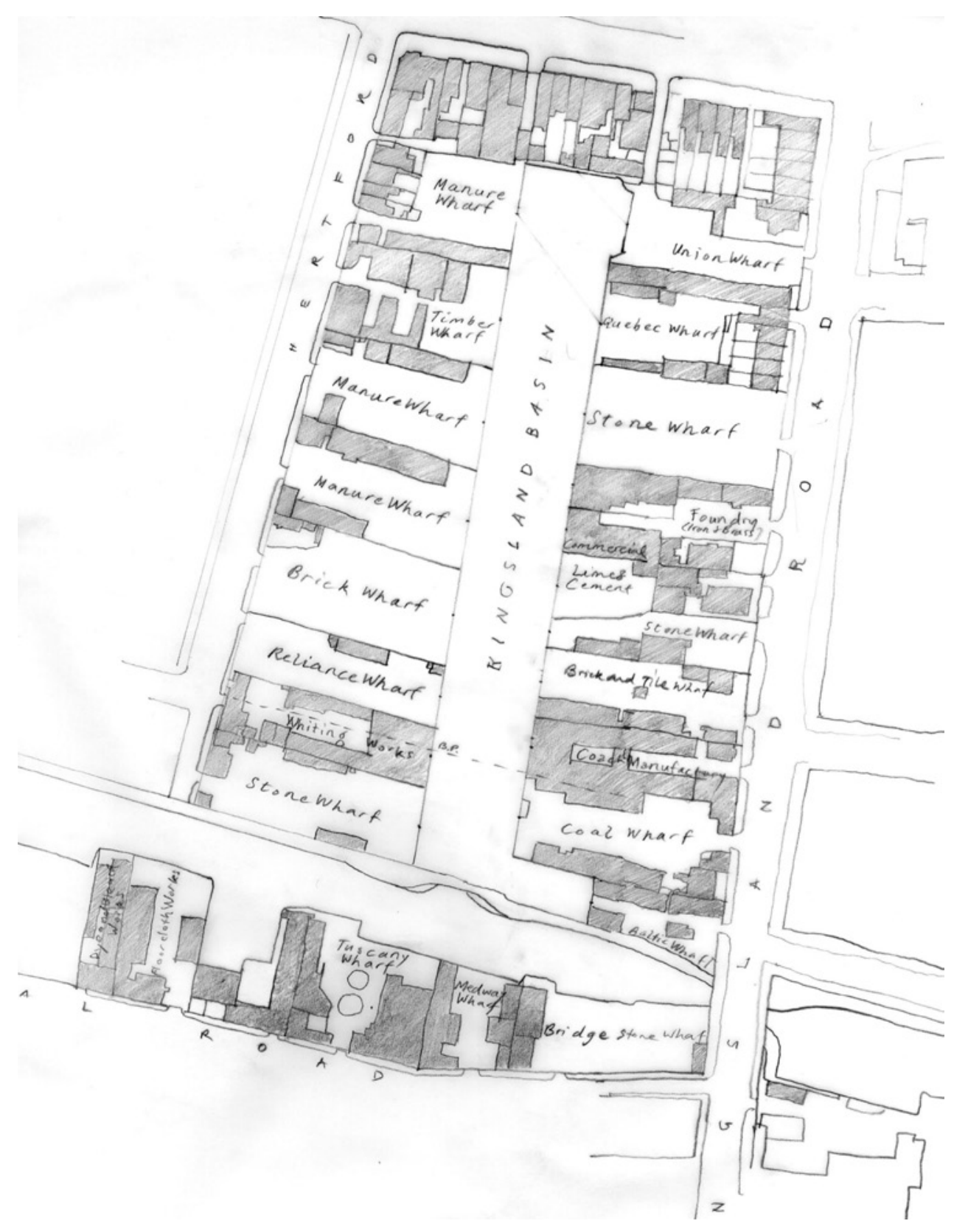

Site Plan of Kingsland Basin, London

(1871) showing past industry. E. Morris.

Pencil on trace 


\section{The Archive of Atmosphere: Installation as an interior architectural event}

Installation at the Bartlett,

London, September 2010

\section{Emma Morris}

To create an interior micro-ecology, this archival project uses the technique of installation and an organisational strategy analogous to the 'natural archive' of an ice core. Ice cores archive climate history: the 'memory' of past temperatures is encoded in air bubbles, and trapped in ice crystals. Scientists analyse this 'information' to forecast future global climate patterns. The longest ice core from Antarctica is " 3207 metres long and covers the last 650,000 years" (Chandler 2005).

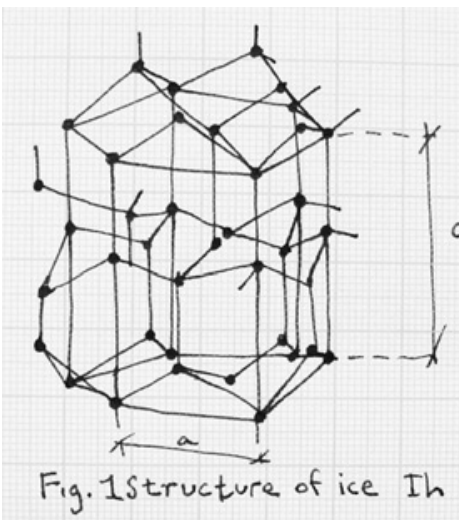

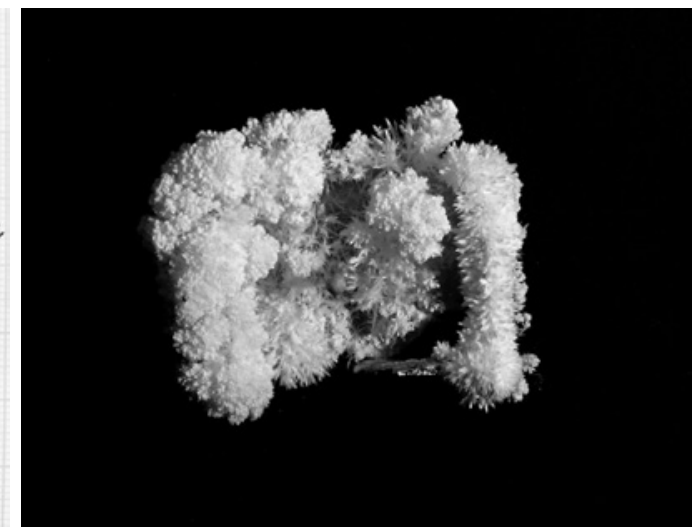

The Archive
The Archive of Atmosphere is an eccentric scientific endeavour. Installed at the Bartlett, the archive used materials sourced from the Kingsland Basin off the Regent's Canal, a remnant of the industrial revolution in East London. The timebased system operated by collecting water from the canal, feeding it into water catchers and mixing it with various chemicals. As "an access to the remains of the past” (Shanks 2010), it sought to make the site's historical narrative visible.

The solution crystallised into solid forms through capillary action and evaporation. The atmospheric particles within the water became embedded in the crystal lattice structure, and preserved for the future. Crystallisation produces a slowly growing build-up of material: as an emergent building technology, it is a synthetic analogue system which manufactures matter (Armstrong 2009).

The archive is a chemical computer, a machine-for-remembering (Borges 1984: 72).

The human technician as archivist interacted with the installation, activating the water flow and phase changes, controlling light, wind flow, and humidity, generating a micro-ecology in the room.
Left: Diagram of the molecular structure of ice, a hexagonal lattice, which forms a container for air bubbles. E. Morris. Pen on paper.

Right: Crystal specimen study. Chemical mix on pewter. 


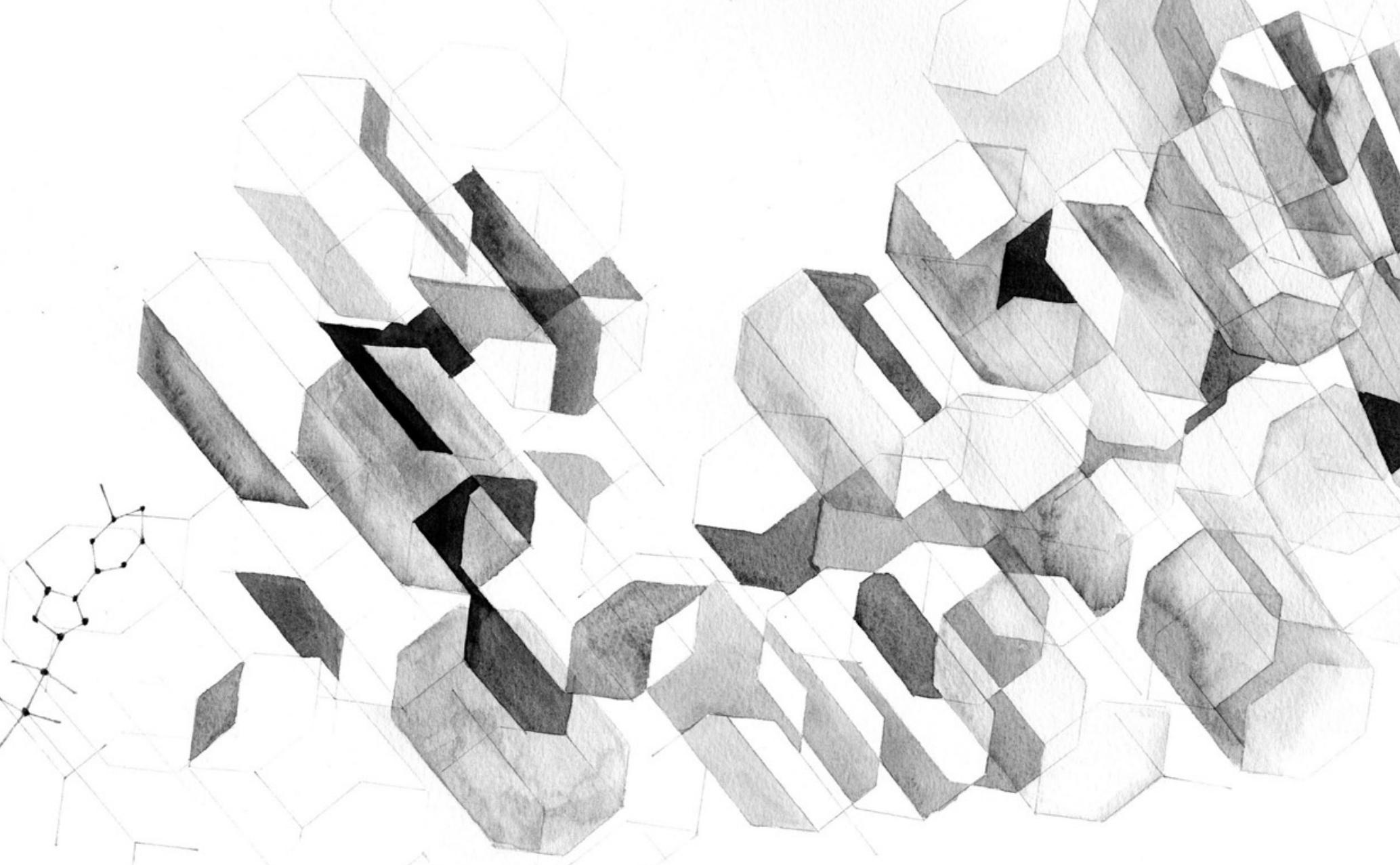




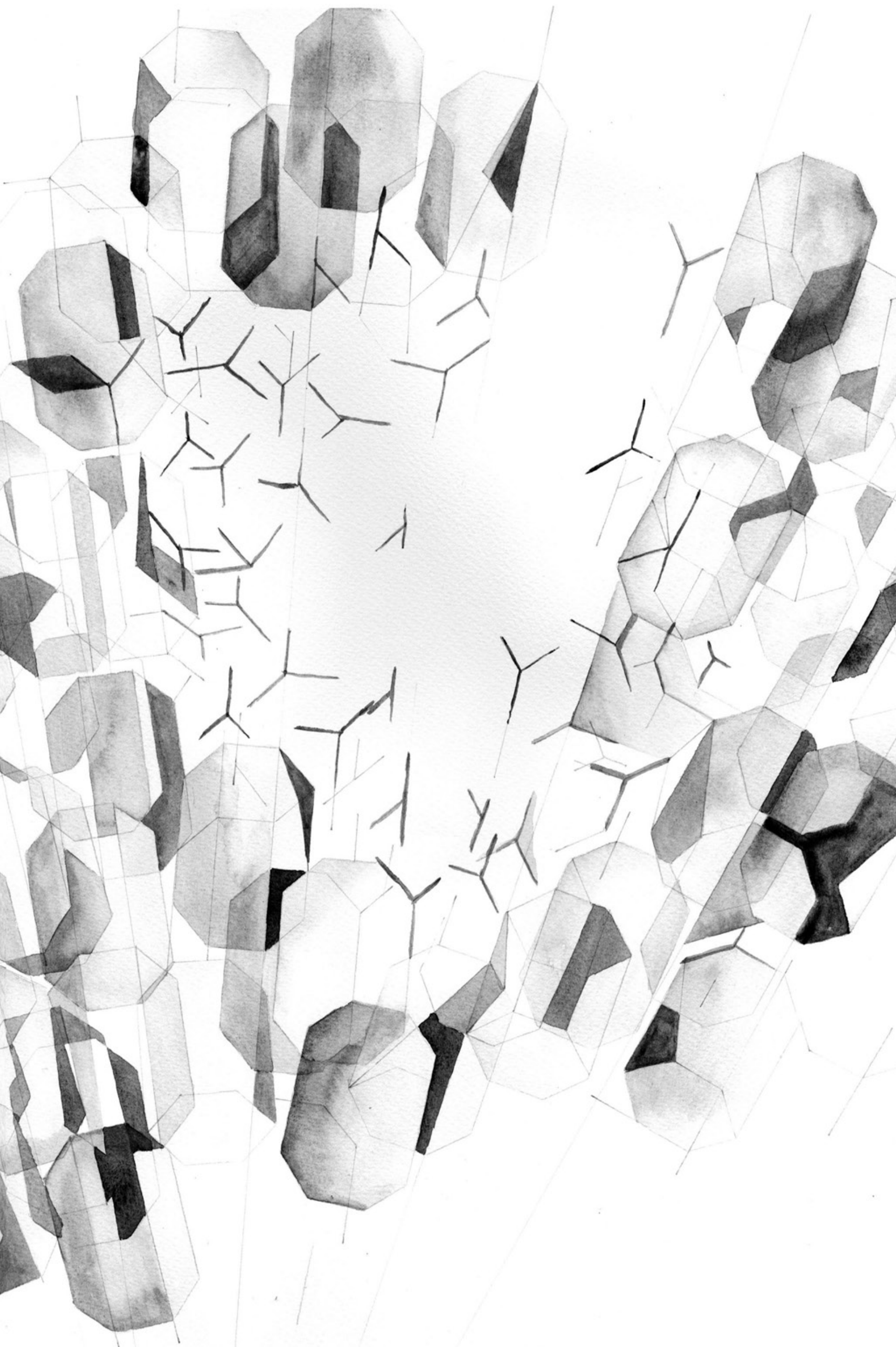




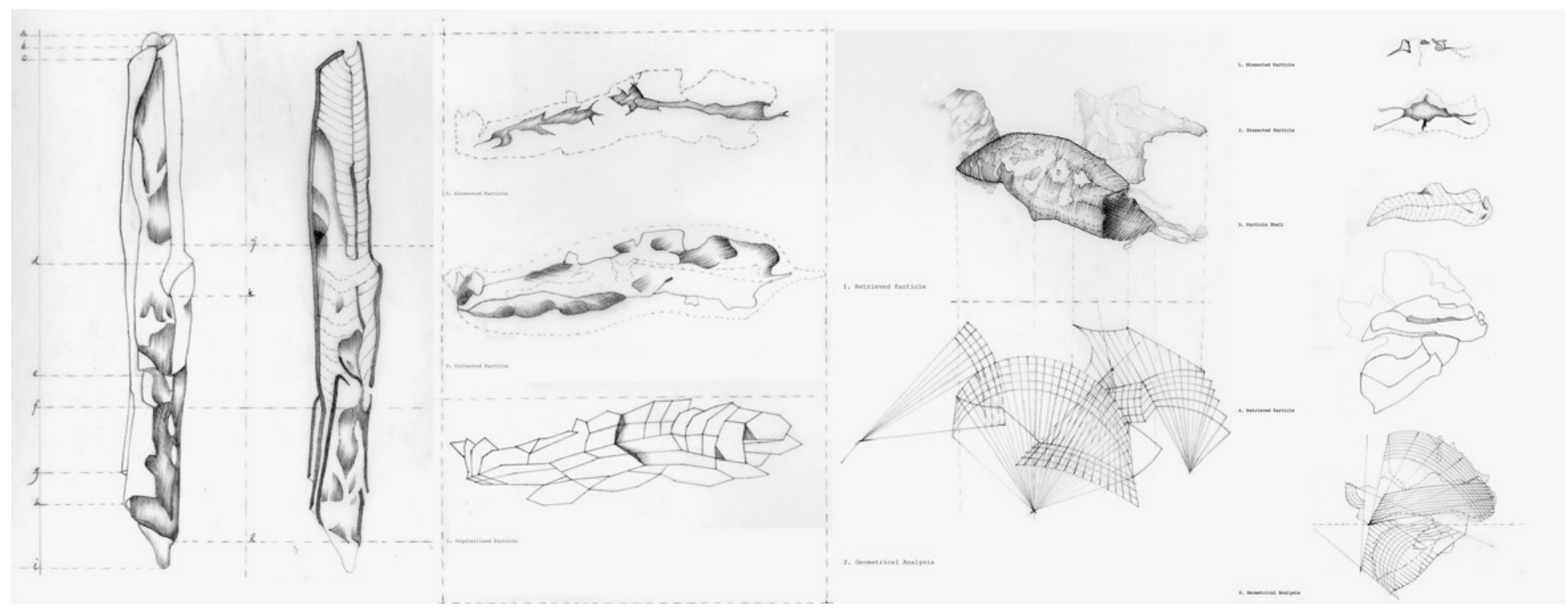

Analysis of atmospheric particles. E. Morris. Pencil on paper.
The archive is an open system, which "interchange[s] matter and energy with the outside" (Fernandez-Galiano 2000: 104). Its collection is sourced from the canal and its form continuously reconfigured according to the crystallisation produced by chemical reactions, as well as the internal climatic conditions of the room.

By recording activities, the installation produces its own 'drawings'. On the paper placed on the floor, there are piles of particles, elements drawn in from the canal: clay, lead, carbon, ash, spices from past industrial trading. Water overspills, drips onto the particles that provide the medium for the drawing.

Archival practices are researched in this project to investigate their creative potential for an architectural strategy. Archival practice is an active and ongoing process of collecting, storing and interpretating of information, where information is "an action which occupies time (Barlow 1994). Archival practice examines the repetitive, obsessive, immersive nature of collecting. It challenges the architect to consider her work as both contributing to and co-producing "an archive in the making” (Foster 2004).

\section{The Installation}

The installation makes reference to the "archival impulse" (Foster 2004) of Kurt Schwitters' Merzbau, his studio as a growing, living archive, a continuous process of collection and transformation (Meyer-Buser 2000); Gerhard Richter's Atlas, his dense installation of work creating a spatial "environment" (Dietrich 1985: 130); and Cornelia Parker's Cold Dark Matter: An Exploded View (1991), a transformation of objects found on site, reassembled and installed in the gallery (Parker 1996). Gego's use of steel wire to draw in three-dimensional space is directly referenced in the geometrical structures of the installation (Ramirez 2006). Installation as a technique reveals the archive as an immersive, interior experience, engaging directly with those who access it. It "force[s] the visitor, both mentally and physically, to enter the work and to succumb with all their senses to the rules of the game" operating in it (Meyer-Buser 2000). For an architectural proposition, the power of the installation is its potential to create an interior immersive experience through the viewer's physical and sensory engagement with the space. The Archive of Atmosphere's ambition is to investigate the potential of archival strategies in these contexts.

The Archive of Atmosphere can be read as an architectural event which gives a physical presence to the invisible - the fragile and unstable atmosphere. Archives, as interior conditions, are a necessary safe-keeper of past collections enabling the prediction of vast external change. 


\section{References:}

Armstrong, R. (2009, August 8). Material (or Chemical) Computing: Protocell example. Rachel Armstrong Living Architect Scrapbook. Retrieved June 10, 2010, from http://grayanat.posterous. com/material-or-chemical-computing-protocell-exam

Barlow, J. P. (1994, March). The Economy of Ideas. Wired. Retrieved August 18, 2011, from http:// www.wired.com/wired/archive/2.03/economy.ideas.html

Borges, J. L. (1984). Atlas. London: Viking.

Chandler, D. (2005, November 24). Record lce Core Reveals Earth's Ancient Atmosphere, New Scientist. Retrieved June 10, 2010, from http://www.newscientist.com/article/dn8369-recordice-core-reveals-earths-ancient-atmosphere.html

Dietrich, D. (1985). Gerhard Richter: An Interview. The Print Collectors Newsletter, 16(4).

Fernande-Galiano, L. (2000). Fire and Memory, On Architecture and Energy. Cambridge, Massachusetts: The MIT Press.

Foster, H. (2004). An Archival Impulse. October, 110. Cambridge, Massachusetts: The MIT Press. Parker, C. (1996). Avoided Object. Cardiff: Chapter.

Meyer-Buser, S. (2000). On Disappearing in Space, Walk in Collages from Schwitters to the Present Day. In S. Meyer-Buser \& K. Orchard, (Eds.), Merz: In the Beginning Was Merz: From Kurt Schwitters to the Present Day. Ostfildern-Ruit: Hatje Cantz Publishers.

Ramirez, M. C., Manrique, J., de Zegher, C. (2006). Gego: Between Transparency and the Invisible Houston: Museum of Fine Arts.

Shanks, M. (2010, February 18). Animating the Archive. Retrieved June 10, 2010, from http:// documents.stanford.edu/MichaelShanks/186

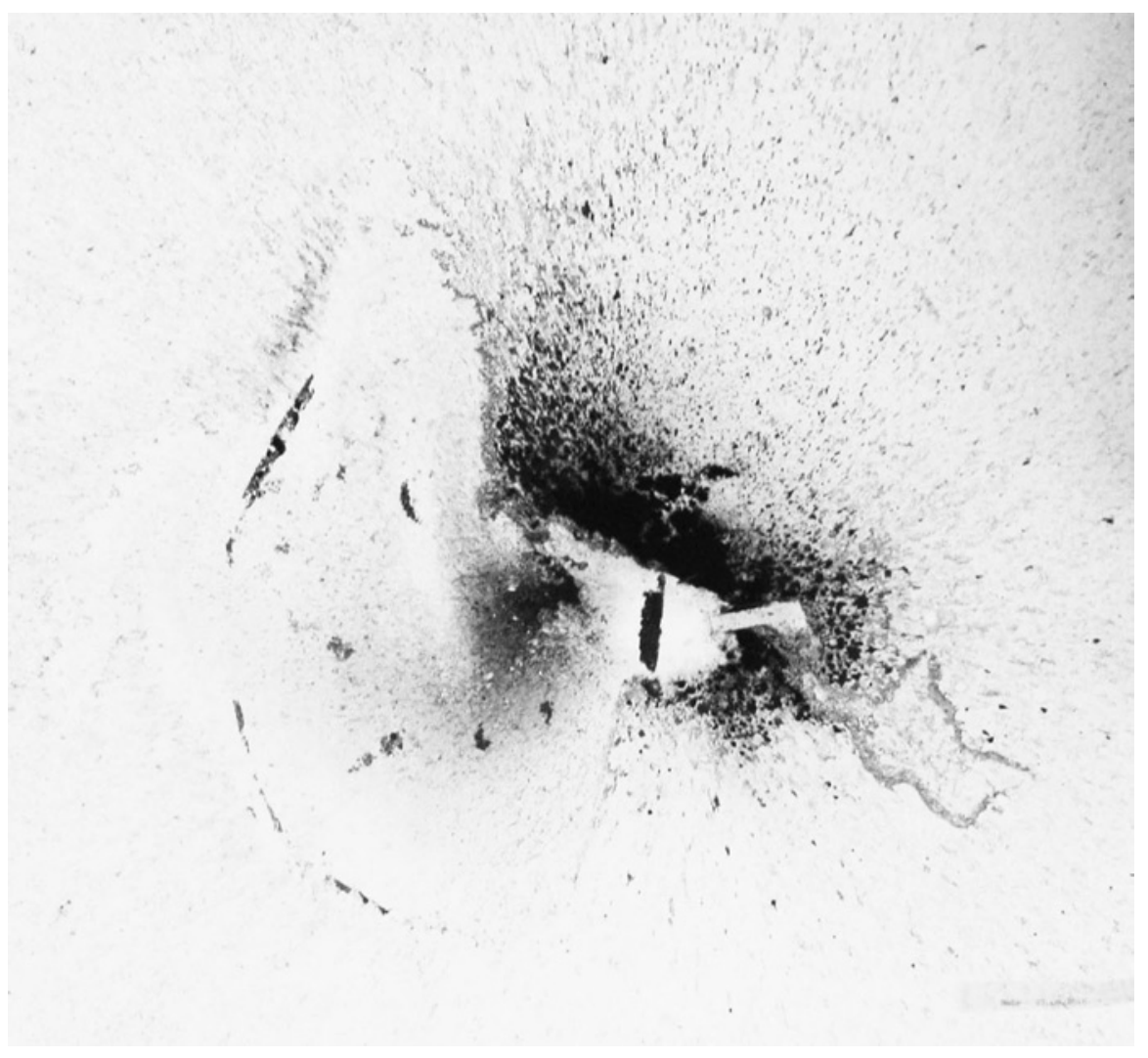

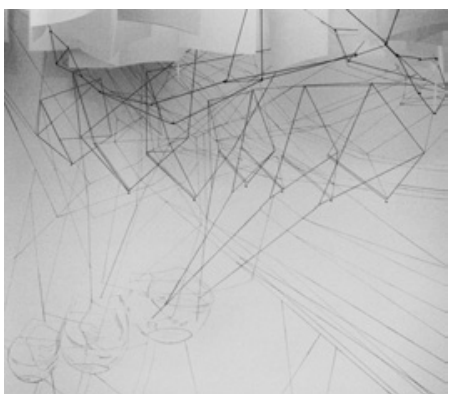

Left: Residue of activity on floor: water drips into particles of various elements. Photograph E. Morris.

Right: Wall drawing traced from projections through installation. E. Morris. Pencil on paper. 

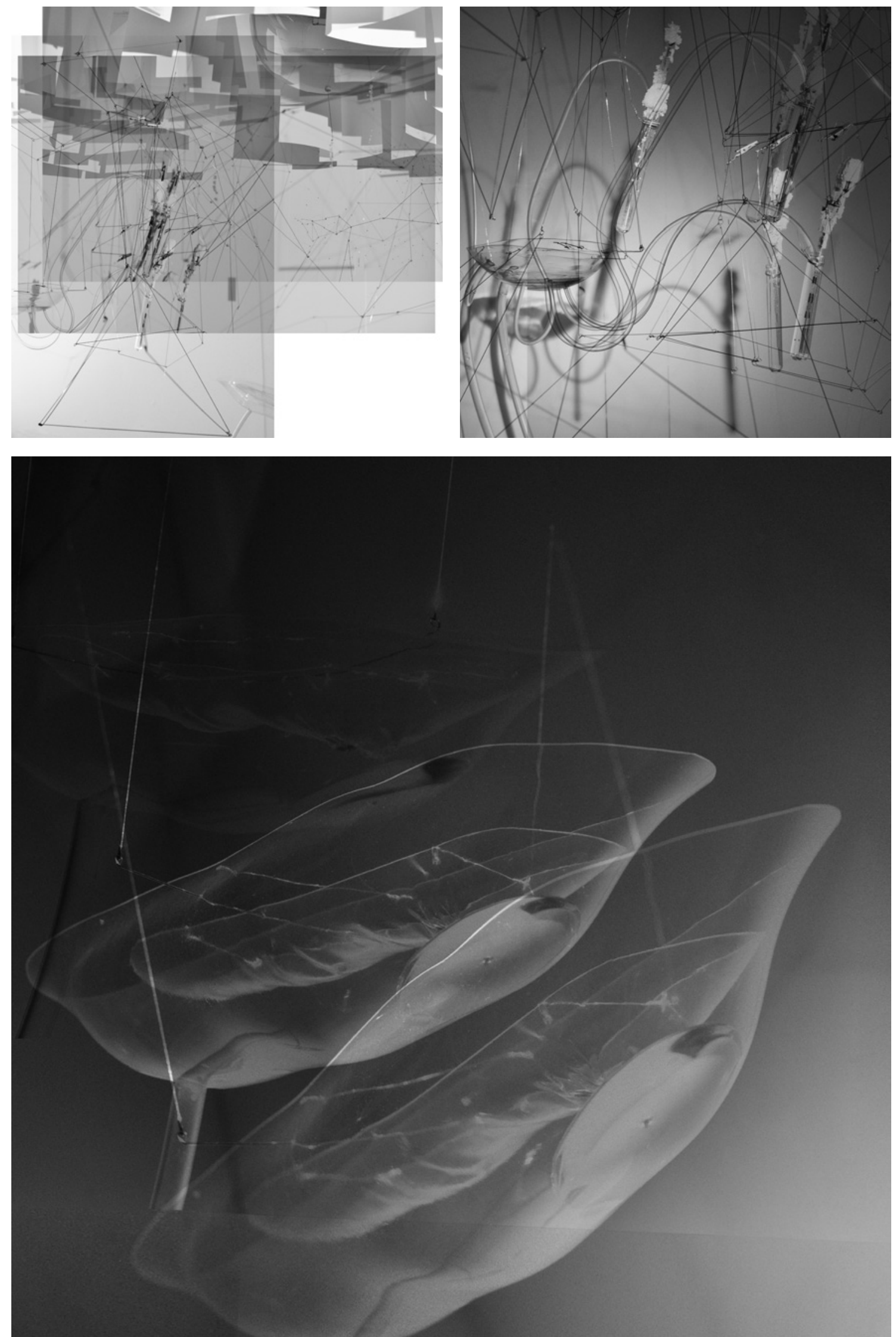

Installation, photographs by Nina Morris. Steel wire, plastic, filter paper, laboratory glassware, crystals. 

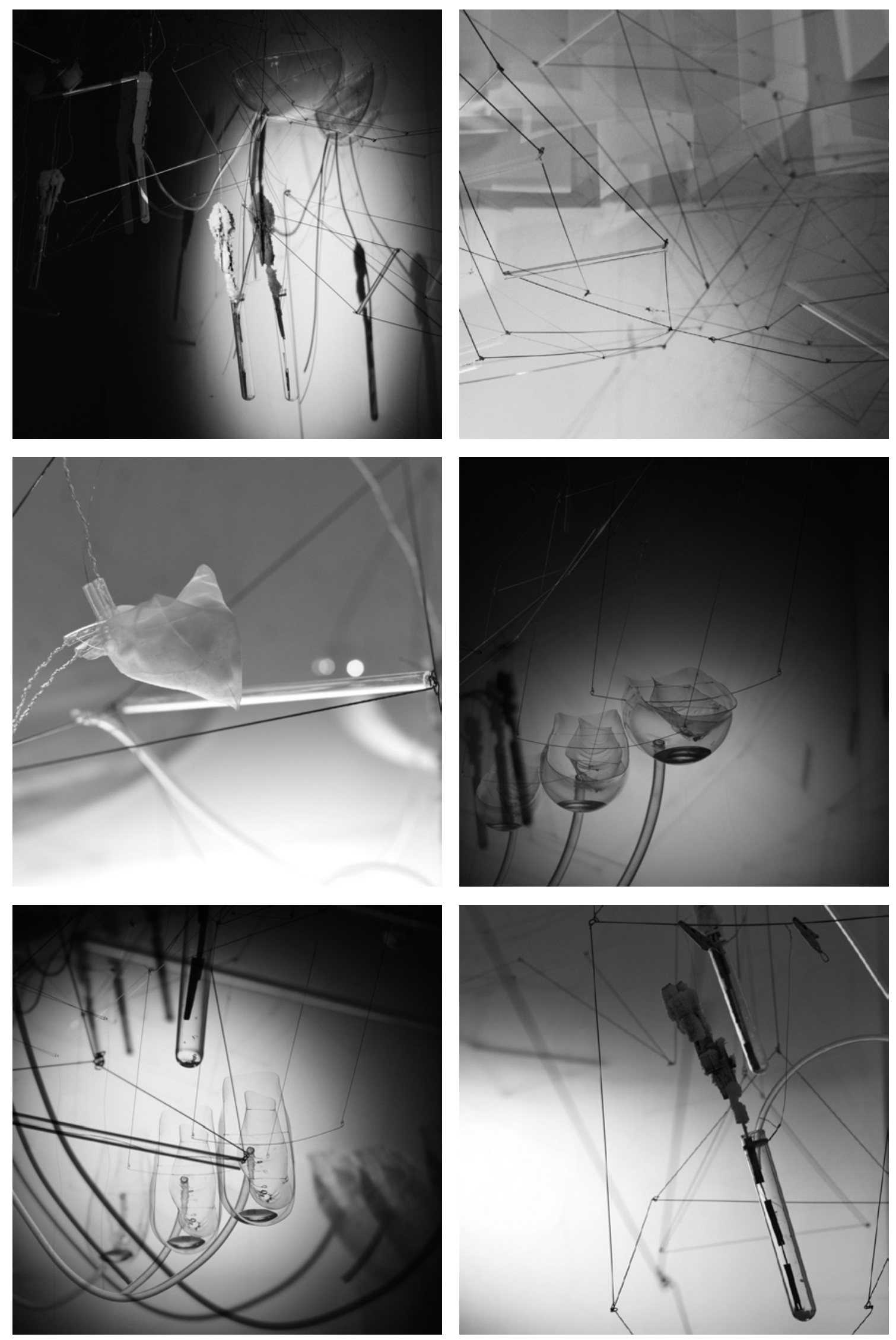